\title{
A comparison of intralesional triamcinolone acetonide injection and incision-curettage for chalazion treatment
}

\author{
Jain A. ${ }^{1}$ \\ ${ }^{1}$ Dr. Abhijit Jain, Assistant Professor, Department of Ophthalmology, Government Medical College, Ambikapur, \\ Chhattishgarh, India
}

Corresponding Author: Dr. Abhijit Jain, Assistant Professor, Department of Ophthalmology, Government Medical College, Ambikapur, Chhattishgarh, India. E-mail: jainabhijit929@gmail.com

\begin{abstract}
Objective: To compare the efficacy of intralesional triamcinolone acetonide with surgical incision and curettage in patients with chalazion. Material and Method: This longitudinal interventional study was carried out during $1^{\text {st }}$ September 2015 to $31^{\text {st }}$ August 2016 at Kamlesh Netralaya Hospital at Ambikapur, Chhattisgarh in central India. Total 60 patients with Chalazion of ( $\geq 2 \mathrm{~mm}$ in size) were randomly divided into two groups of 30 patients each. The first group of patients $(\mathrm{N}=30)$ was treated by 0.1 to $0.2 \mathrm{~mL}$ intralesional triamcinolone acetonide injection $(40 \mathrm{mg} / \mathrm{mL})$ and the second group of patients $(\mathrm{N}=30)$ were treated surgically by incision-curettage. Post steroid injection, the reduction in chalazion size was measured at 2 weeks and at 4 weeks. Results: Out of 60 patients, $58.33 \%$ were females with mean age of $31.8 \pm 9.1$ years. There were total 79 chalazion in two groups. Among those treated using intralesional triamcinolone acetonide (ILTA), 29 (70.73\%) chalazion resolved at 2 week. The unresolved chalazion were repeated the ILTA injection at $2^{\text {nd }}$ week and followed till 4 week. The mean 11-point numerical rating scale (NRS) score for pain intensity was significantly lower in ILTA group as compared to IC group $(2.3 \pm 0.42$ vs $6.7 \pm 1.2$, P-value $=0.001)$. Conclusion: The results of intralesional triamcinolone acetonide injection treatment are comparable to that of surgical incision and curettage (IC) after second injection. Patients experienced less pain and were more satisfied with the intralesional triamcinolone acetonide injection.
\end{abstract}

Keywords: Chalazion, Intralesional injection, Triamcinolone acetonide, Incision and curettage.

\section{Introduction}

Localized cyst on eyelids consisting of lipogranulomatous inflammation is called as Chalazion [1]. In India, among general population, the incidence of chalazion is $0.24 \%$. The incidence was found higher in females as compared to males [2]. Commonly, they are unsightly, and if large in size can induce mechanical ptosis and cause blurred vision from induced astigmatism by pressing the cornea $[1,3]$. Rarely, it can also lead to conjunctivitis or cellulitis. It is caused by the blockage of gland orifices and stagnation of sebaceous secretions in the tarsus of an eyelid. Pathologically, a chalazion is composed of chronic lipogranulomatous inflammatory changes, probably as a result of chronic irritation with low virulent microorganisms, and histologically, it is an epitheloid granuloma, which is predominantly composed of corticosteroid - sensitive histiocytes, mononuclear

Manuscript received: $30^{\text {th }}$ November 2018

Reviewed: $5^{\text {th }}$ December 2018

Author Corrected; $10^{\text {th }}$ December 2018

Accepted for Publication: $15^{\text {th }}$ December 2018 granulocyte cells, lymphocytes, plasma cells, polymorphonuclear cells and eosinophils [4,5].

Individuals of all ages can be affected, but more frequently it appears in adults. Clinically, it can present as uniform or multiple, as well as recurrent. Most commonly, it appears on the upper eyelid, which can be explained by the presence of more glands on the upper eyelid by anatomical distribution [6].

Chalazion can be managed conservatively using warm compress and antibiotic eye ointment for the prevention of secondary bacterial infection. For persistent lesions, incision and curettage (I \& C), steroid injection, or carbon dioxide laser treatment may be considered [5,7]. Incision and curettage requires referral to an ophthalmologist, and involve complications like pain, bleeding, and scarring. Intralesional steroid injection for chalazion has been reported to be effective with high success rates [7-14]. 


\section{Original Research Article}

This treatment modality is particularly useful in children and in patients where cooperation for incision and curettage is difficult. Hence, the present study was conducted with the objective of to compare the efficacy of applied therapy in two groups of patients with chalazion, one undergoing incision and curettage and the other giving intralesional triamcinolone acetonide on chalazion.

\section{Material and Method}

Study design- longitudinal interventional study

Place of study- Kamlesh Netralaya Hospital, at Ambikapur, in Chhattisgarh in central India.

Study Duration- The study was conducted during $1^{\text {st }}$ September 2015 to $31^{\text {st }}$ August 2016.

Study Participants- Study subjects were diagnosed and admitted cases of Chalazion ( $\geq 2 \mathrm{~mm}$ in size) with no previous history of lid surgery or trauma and consenting to participate during study period. Patients having acutely inflamed lesions, multiple chalazion and previous known ocular side effects of steroids were excluded.

Sample size- Fulfilling the inclusion and exclusion criteria, total 60 patients with primary chalazion were included in study. These patients were randomly divided into two groups of 30 patients each based on table of random numbers. The first group of patients $(\mathrm{N}=30)$ was treated by intralesional triamcinolone acetonide injection (ILTA) $(0.1$ to $0.2 \mathrm{~mL}(40 \mathrm{mg} / \mathrm{mL})$ and the second group of patients $(\mathrm{N}=30)$ were treated surgically (incision-curettage) (IC).

The participation of patients was on voluntary basis, written informed consent was obtained from study participants, anonymity and confidentiality was assured and emphasized. During data collection vital status of study subjects was assessed and if they were in the position to give interview, then only the data was collected by interview technique.

A detailed medical history was obtained and ocular examination of the patients was done. Visual acuity, slit lamp biomicroscopy, intraocular pressure measurement, dilated fundoscopy were performed on patients. The size of the chalazion was measured to the nearest millimeter from the skin surface, across its widest dimension, before and after the procedure. The patient was re-examined after 2 weeks and if chalazion persisted, the triamcinolone injection was repeated.
1 month postoperatively the patients were reexamined. Efficacy (resolution) of treatment was considered as reduction in chalazion size to less than $2 \mathrm{~mm}$ after steroid injection at 4 weeks follow up visit. Complications of procedure like skin pigment changes, skin atrophy, pyodermisation, post surgical hematoma were also looked along with time of resolution of chalazion after procedure. All the relevant details were documented on a pre devised proforma.

Score used for pain assessment- For assessment of pain, a simplified version of the 11-point Numerical Rating Scale was used [15]. In which the overall experience of pain was scored on a scale of 0 to 10 . Wherein 0 mean - I did not feel anything during the surgery, and 10 meant - I felt the worst pain. Similarly, for assessing satisfaction Likert scale ${ }^{b}$ was used, which has five levels of satisfaction, in which one (1) meant- I am very unsatisfied and five (5) meant - I am extremely satisfied.

Intervention include transconjunctival application of 0.2 $\mathrm{ml}$ of $40 \mathrm{mg} / \mathrm{ml}$ triamcinolone acetonide through 28 gauge needle on a $1 \mathrm{ml}$ insulin syringe on chalazion, after local anaesthesia (EMLA 5\% ointment). After the procedure, eyes were not occluded but patients were given chloramphenicol ointment to apply on the treated eye thrice a day and instructed to apply gentle digital massage over the chalazion for 5 minutes thrice a day for 5 days.

In surgical treatment, the eyelid was anaesthetize using transcutaneous 2\% lignocaine with 1:10000 adrenaline, and the conjunctiva was anaesthetized with a drop of $0.5 \%$ proxymethocaine; using cyst clamp the eyelids were everted, vertical incision was given on tarsal conjunctiva and curettage of the chalazion was done.

An antibiotic ointment and ocular compressive occlusion was done, after the surgical procedure. Patients were given chloramphenicol ointment four times a day for 1 weak to apply in the eye. Patients were followed up 7 days after the surgery to evaluate possible local complications and 3 weeks after the surgery to assess the withdrawal of the chalazion.

Statistical: The data was entered in Microsoft excel 2007.All the continuous variable was summarized using mean \& SD while the categorical variables as percentage \& proportion. For showing the association student $\mathrm{t}$ test was applied on continuous variables while chi-square test was applied for categorical variables. The significance considered when the $\mathrm{p}$ value is less than 0.05 . 


\section{Result}

Table No.1 show that out of 60 patients, maximum, 35 (58.33\%) were females. Mean age of male patients was $32.1 \pm 9.2$ and female patient was $31.8 \pm 9.1$ years. Mean duration of chalazion in female patients was $6.8 \pm 1.7$ weeks. 18 (72\%) of male patients and $23(65.71 \%)$ of female patients had unilateral chalazion. Out of total 79 chalazion in two groups, maximum 47 (59.49\%) were present in female patients. Among, 47 chalazion in female patients, 14 (29.79\%) were in left upper eyelid. Table no 2. Shows that, out of total 30 patients which undergone intralesional triamcinolone acetonide treatment $17(56.67 \%)$ were females. 18 (60\%) female underwent incision and curettage. Maximum, 41(51.90\%) chalazion were treated using intralesional triamcinolone acetonide and $38(48.10 \%)$ chalazion were treated by incision and curettage. $2(5.26 \%)$ secondly recurred chalazion were treated by incision and curettage. No secondly recurred chalazion was treated using intralesional triamcinolone acetonide. 19 (46.34\%) firstly recurred chalazion were treated using intralesional triamcinolone acetonide treatment. Pre treatment size of $32(78.05 \%)$ of chalazion undergone intralesional triamcinolone acetonide treatment and 27 (71.05\%) chalazion undergone incision and curettage was 2-6 mm in size. As per table no 3, among the 41 chalazion which were treated using intralesional triamcinolone acetonide treatment, $29(70.73 \%)$ were resolved at 2 week. Among the 12 unresolved chalazion, all were repeated the intralesional triamcinolone acetonide treatment at $2^{\text {nd }}$ week and followed till 4 week and total $37(90.24 \%)$ resolved at 4 week. The remaining $4(9.76 \%)$ unresolved chalazion were treated by incision and curettage. The results of intralesional triamcinolone acetonide treatment are comparable to that of surgical incision and curettage after second injection. The mean 11-point numerical rating scale (NRS) score for pain intensity was significantly lower in ILTA group as compared to IC group $(2.3 \pm 0.42$ vs $6.7 \pm 1.2, \mathrm{P}$-value $=0.001)$. For assessing satisfaction Likert scale was used, ILTA group had mean score of $3.8 \pm 1.1$ while IC group had $1.3 \pm 0.27$, which was found to be statistically significant with p-value being 0.001. ILTA was significantly associated with lesser pain and better patients satisfaction in chalazion treatment as compared to incision and curettage.

Table No.-1: Distribution of study subjects according to gender and laterality of chalazion

\begin{tabular}{|l|c|c|c|c|}
\hline Characteristic & \multicolumn{2}{|c|}{ Male } & \multicolumn{2}{c|}{ Female } \\
\hline Total Patients (N=60) & $\mathbf{N o}$ & $\mathbf{\%}$ & $\mathbf{N o}$ & $\mathbf{\%}$ \\
\cline { 2 - 5 } & 25 & 41.67 & 35 & 58.33 \\
\hline Mean Age (yrs) & $32.1 \pm 9.2$ & & $31.8 \pm 9.1$ & \\
\hline Duration of chalazion (weeks) & $6.4 \pm 1.3$ & & $6.8 \pm 1.7$ & $\mathbf{N}$ \\
\hline Total Chalazion (N=79) & $\mathbf{N = 3 2}$ & $\mathbf{4 0 . 5 1}$ & 12 & 25.53 \\
\hline Right upper eyelid & 8 & 25.00 & 11 & 23.40 \\
\hline Right lower eyelid & 7 & 21.88 & 14 & 29.79 \\
\hline Left upper eyelid & 10 & 31.25 & 10 & 21.28 \\
\hline Left lower eyelid & 7 & 21.88 & $\mathbf{N}=\mathbf{3 5}$ & \\
\hline Laterality & $\mathbf{N = 2 5}$ & & 23 & 65.71 \\
\hline Unilateral chalazion & 18 & 72.00 & 12 & 34.29 \\
\hline Bilateral Chalazion & 7 & 28.00 & & \\
\hline
\end{tabular}

Table No.-2: Distribution of study subjects according to intervention done

\begin{tabular}{|c|c|c|c|c|c|}
\hline \multirow[t]{2}{*}{ Characteristics } & \multirow[t]{2}{*}{ Intervention } & \multicolumn{2}{|c|}{$\begin{array}{c}\text { Intralesional Triamcinolone } \\
\text { Acetonide }(\mathrm{N}=\mathbf{3 0})\end{array}$} & \multicolumn{2}{|c|}{$\begin{array}{c}\text { Incision \& Curettage } \\
(\mathbf{N}=\mathbf{3 0})\end{array}$} \\
\hline & & No & $\%$ & No & $\%$ \\
\hline \multirow[t]{2}{*}{ Gender } & Male & 13 & 43.33 & 12 & 40 \\
\hline & Female & 17 & 56.67 & 18 & 60 \\
\hline Chalazion $(\mathrm{N}=79)$ & & $\mathrm{N}=41$ & 51.90 & $\mathrm{~N}=38$ & 48.10 \\
\hline \multicolumn{2}{|l|}{ New } & 22 & 53.66 & 21 & 55.26 \\
\hline \multicolumn{2}{|l|}{ First recurrence } & 19 & 46.34 & 15 & 39.47 \\
\hline \multicolumn{2}{|l|}{ Second recurrence } & 0 & 0.00 & 2 & 5.26 \\
\hline \multirow{4}{*}{$\begin{array}{l}\text { Pre-treatment size of } \\
\text { chlazion }(\mathrm{mm})\end{array}$} & & $\mathrm{N}=41$ & $\%$ & $\mathrm{~N}=38$ & $\%$ \\
\hline & $2-6.00$ & 32 & 78.05 & 27 & 71.05 \\
\hline & $6.01-9.00$ & 7 & 17.07 & 8 & 21.05 \\
\hline & $>9.01$ & 2 & 4.88 & 3 & 7.89 \\
\hline
\end{tabular}


Original Research Article

Table No.-3: Distribution of study subjects according to status of chalazion after treatment.

\begin{tabular}{|l|c|c|c|c|}
\hline $\begin{array}{l}\text { Intralesional Triamcinolone Acetonide } \\
\text { (N=41) }\end{array}$ & At 2nd week & \% & At 4th week & \% \\
\hline Resolved & 29 & 70.73 & 37 & 90.24 \\
\hline Not Resolved & 12 & 29.27 & 04 & 9.76 \\
\hline
\end{tabular}

\section{Discussion}

Complete healing with less anxiety and discomforts to patients are the advantages of intralesional triamcinolone acetonide over surgical procedure for primary and recurrent chalazion treatment. In our study, out of 60 patients, which undergone for chalazion resolution by either treatment, maximum (58.33\%) were females. Out of total 79 chalazion in two groups, maximum 47(59.49\%) were present in female patients. The higher incidence of chalazion among female patients in our study is consistent with that of Kumar $\mathbf{J}$ et al who also found higher incidence of chalazion in females (68\%) as compared to males (32\%) [2]. In our study, mean age of male patients was $32.1 \pm 9.2$ and female patient was $31.8 \pm 9.1$ years. Kumar $\mathbf{J}$ et al also found maximum incidence in patients less than 30 year or equal to 30 year of age $(72 \%)$.

This can be explained by higher level of androgenic hormones which increases sebum viscosity. Hormonal influence on sebaceous secretion and viscosity can be explained by clustering during puberty and pregnancy. In our study, among 47 chalazion in female patients, $14(29.79 \%)$ were in left upper eyelid. This observation is also consistent with that of Kumar $\mathrm{J}$ et al in which maximum incidence was seen in upper lid (77.50\%) because the numbers of meibomian glands are higher in upper lid [2].

In our study, 12 chalazion required one more injection of triamcinolone acetonide. It did not affect the result nor caused any discomfort to patients and are comparable with that of Ben Simon G.J et al and Prasad S et al [10,16]. Intralesional triamcinolone acetonide had complication like hypopigmentation, atrophy of the area, corneal perforation, traumatic cataract, retinal and choroidal vascular occlusion and inadvertent globe penetration. In our study no complication following intralesional triamcinolone acetonide injection was observed. The transconjunctival route of TA injection as in our study was found to be safe and consistent with the observations of Ben Simon and other studies [10,17-18]. We observed that transconjunctival route of TA injection appears to avoid localized skin depigmentation, or inadvertent penetration of the globe. Ho observed in his study that out of the 48 patients that underwent subcutaneous intralesional triamcinolone injection, two were affected by localized skin depigmentation whereas in our study, none of the 30 patients that underwent this procedure suffered any localized skin depigmentation [19].

Our study supports the notion that the transconjunctival route of TA injection minimizes the risk of localized skin depigmentation. One possible explanation for this could be that although the injection is aimed at being deposited intralesionally, occasionally a small portion of TA may be deposited by the needle on the way in or out of the injection site. Previous studies investigating the efficacy of TA in the treatment of chalazia have used varying concentrations of the drug. Ho and Lai used a triamcinolone acetonide concentration of $10 \mathrm{mg} / \mathrm{mL}$, Simon et al. used TA in concentration of 40 $\mathrm{mg} / \mathrm{mL}$, which we had used in our study [10,19]. Ahmed S had reported an even lower concentration of injected TA (5 $\mathrm{mg} / \mathrm{mL}$ ) being efficacious [16]. Goawalla and Lee report on only $0.2 \mathrm{mg} / \mathrm{mL}$ dilution to minimize the risk of localized skin depigmentation and did not document any case of adverse effect in a total of 56 patients [8]. Further studies investigating how the efficacy of intralesional triamcinolone varies with different concentrations are required to answer this important question.

Generally, we saw that patients did not preferred to undergo any operative procedure. The operative procedure are costlier and involves anaesthetic injection, longer follow up period, hence people had psychological aversion to surgery. It was observed that in infected chalazion or those chalazion which did not respond to eyelid hygiene and steroid injection, surgical incision and curettage is effective. Although TA frequently effective, in various studies it was observed that intralesional triamcinolone injections need to be repeated for complete chalazion resolution, which is consistent with our observation [16-19]. This had affected the convenience of the patients. As in our study, Bolton JE had also used Numerical Rating Scores for assessment of pain. Comparing with the Visual Analogue Scale and the Verbal Rating Scale, for assessment of pain the Numerical Rating Scores was found to be superior in a previous studies too [15]. 


\section{Original Research Article}

Numerical Rating Scale was found to be easy for scoring by patients, to analyse and to yield consistent results, so our study supports the use of Numerical Rating Scale for assessment of pain in treatment evaluative trials.
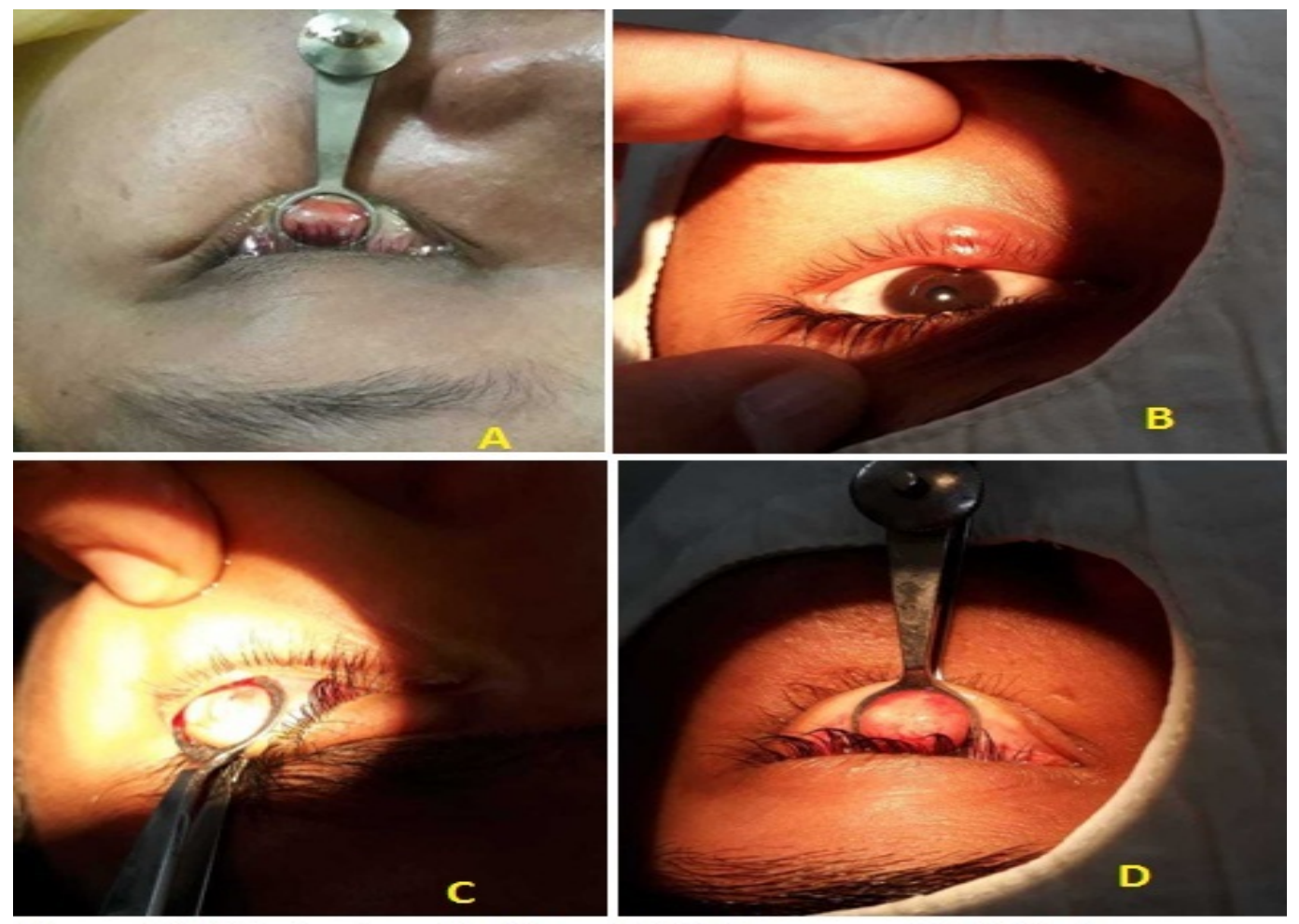

Fig no. 1 (A) Chalazion with clamp (B,C,D) lower eyelid chalazion

In addition to having a resolution rate comparable with conventional I \& $\mathrm{C}$, triamcinolone injections theoretically avoid excessive bruising of the lid as it is far less traumatic. Not needing an eye-pad post treatment means that patients can drive and resume their daily activities almost immediately following treatment. Intralesional triamcinolone injections for chalazia have obvious economic and practical advantages for the health-care provider as its cost in time and equipment is a fraction of that for conventional surgical treatment. TA injections are therefore a good first-line treatment option for uncomplicated chalazia and could be administered by trained nurse practitioners in the eye clinic or even in a primary health-care setting. Following intralesional injection of triamcinolone, retinochoroidal vascular occlusion leading to anterior segment ischemia is the most serious complication, which should be taken care of during the procedure [20].

Also, in young patients, recurrent chalazion that are not responding to treatment, should be evaluated for pleomorphic adenoma of lacrimal gland, eyelid carcinoma or sebaceous gland carcinoma [21-23]. Our patients were satisfied with the intralesional triamcinolone acetonide injection, and in most cases they preferred repeat injections to surgery [24-26].

What this study adds to existing knowledge? Triamcinolone acetonide injection is more simple to administer with less pain, cost and equipment needed to treat lesion and thus patients can resume their daily activities almost immediately following treatment and it requires minimal facilities when compared to conventional surgical treatment of incision and curettage.

\section{Funding: Nil, Conflict of interest: Nil Permission from IRB: Yes}

\section{References}

1. Donaldson MJ, Gole GA. Amblyopia due to inflamed chalazion in a 13-month old infant. Clin Exp Ophthalmol. 2005 Jun; 33(3):332-3. DOI:10.1111 /j.1442-9071.2005.00982.x

2. Kumar J, Pathak KA, Verma A, Dwivedi S. Study of incidence and risk factors of chalazion in Bundelkhand region. Journal of Dental and Medical Sciences. 2017;16(5) : 5-8. DOI: 10.9790/0853-1605080508.

3. S. Rumelt and P. A. Rubin, "Potential Sources for Orbital Cellulitis," International Ophthalmology Clinics.1996; 36(3): 207-221. doi:10.1097/00004397199603630-00019 


\section{Original Research Article}

4. Perry HD, Serniuk RA. Conservative treatment of chalazia. Ophthalmology. 1980 Mar;87(3):218-21.

5. Pizzarello LD, Jakobiec FA, Hofeldt AJ, et al. Intralesional corticosteroid therapy of chalazia. Am J Ophthalmol. 1978 Jun;85(6):818-21.

6. McGrath NM, Kent-Smith B, Sharp DM. Reversible optic neuropathy due to metronidazole. Clin Exp Ophthalmol. 2007 Aug; 35 (6): 585-6. Clin Exp Ophthalmol. 2007 Aug; 35(6):585-6.

7. Palva J, Pohjanpelto PE. Intralesional corticosteroid injection for the treatment of chalazia. Acta Ophthalmol (Copenh). 1983 Oct; 61(5):933-7.

8. Goawalla A, Lee V. A prospective randomized treatment study comparing three treatment options for chalazia: triamcinolone acetonide injections, incision and curettage and treatment with hot compresses. Clin Exp Ophthalmol. 2007 Nov;35 (8): 706-12. DOI: 10.1111/j.1442-9071.2007.01617.x

9. Ben Simon GJ, Rosen N, Rosner M, et al. Intralesional triamcinolone acetonide injection versus incision and curettage for primary chalazia: a prospective, randomized study. Am J Ophthalmol. 2011 Apr;151(4):714-718.e1. doi:10.1016/j.ajo. 2010.10.026. Epub 2011 Jan 22.

10. Ben Simon GJ, Huang L, Nakra T, et al. Intralesional triamcinolone acetonide injection for primary and recurrent chalazia: is it really effective? Ophthalmology 2005 May;112(5):913-7. DOI:10.1016/ j.ophtha.2004.11.037

11. Pavicić-Astalos J , Iveković R, Knezević T, et al. Intralesional triamcinolone acetonide injection for chalazion. Acta Clin Croat. 2010 Mar;49(1):43-8.

12. Castrén J, Stenborg T. Corticosteroid injection of chalazia. Acta Ophthalmol (Copenh). 1983 Oct;61(5): 938-42.

13. Kaimbo Wa Kaimbo D, Nkidiaka MC. et al. [Intralesional corticosteroid injection in the treatment of chalazion]. J Fr Ophtalmol. 2004 Feb;27(2):149-53.

14. Mustafa TA, Oriafage IH. Three methods of treatment of chalazia in children. Saudi Med J. 2001 Nov; 22(11):968-72.

15. Bolton JE, Wilkinson RC. Responsiveness of pain scales: a comparison of three pain intensity measures in chiropractic patients. J Manipulative Physiol Ther. 1998 Jan;21(1):1-7.

16. Prasad S, Gupta AK. Subconjunctival total excision in the treatment of chronic chalazia. Indian $\mathbf{J}$ Ophthalmol. 1992 Oct-Dec; 40 (4):103-5.

17. Ahmad S, Baig MA, Khan MA, et al. Intralesional corticosteroid injection vs surgical treatment of chalazia in pigmented patients. J Coll Physicians Surg Pak. 2006 Jan;16 (1):42-4.

18. Khurana AK, Ahluwalia BK, Rajan C. et al. Chalazion therapy. Intralesional steroids versus incision and curettage. Acta Ophthalmol (Copenh). 1988 Jun;66 (3):352-4.

19. Ho SY, Lai JS. Subcutaneous steroid injection as treatment for chalazion: prospective case series. Hong Kong Med J. 2002 Feb;8(1):18-20.

20. Jackson TL, Beun L. A prospective study of cost, patient satisfaction, and outcome of treatment of chalazion by medical and nursing staff. $\mathrm{Br} \quad \mathrm{J}$ Ophthalmol. $2000 \mathrm{Jul} ; 84$ (7):782-5.

21. Yağci A, Palamar M, Eğrilmez S, et al. Anterior segment ischemia and retinochoroidal vascular occlusion after intralesional steroid injection. Ophthalmic Plast Reconstr Surg. 2008 Jan-Feb; 24(1) : 55-7. doi: 10.1097/ IOP.0b013e31815c938f.

22. Ramlee N, Ramli N, Tajudin LS. Pleomorphic adenoma in the palpebral lobe of the lacrimal gland misdiagnosed as chalazion. Orbit 2007; 26(2):137-9. DOI:10.1080/01676830600985882.

23. Rawlings NG, Brownstein S, Jordan DR. Merkel cell carcinoma masquerading as a chalazion. Can J Ophthalmol. 2007 Jun; 42(3):469-70. DOI:10.3129/can j ophthalmol.i07-059

24. Moustafa B, Wirbelauer C, Haberle H, Herbst H, Pham DT. Therapy refractory blepharoconjunctivitis in a 90-year-old patient. Ophthalmologe 2007;104:889-91.

25. Chung CF, Lai JS, Li PS. Subcutaneous extralesional triamcinolone acetonide injection versus conservative management in the treatment of chalazion. Hong Kong Med J. 2006 Aug;12(4):278-81.

26. Smythe D, Hurwitz JJ, Tayfour F. The management of chalazion: a survey of Ontario ophthalmologists. Can J Ophthalmol. 1990 Aug; 25(5):252-5.

\section{How to cite this article?}

Jain A. A comparison of intralesional triamcinolone acetonide injection and incision-curettage for chalazion treatment. Trop J Ophthalmol Otolaryngol.2018;3(4):103-108.doi: 10.17511/jooo.2018.i04.08 